\title{
A new species of Leucothoid Amphipod, Anamixis bananarama, sp. n., from Shallow Coral Reefs in French Polynesia (Crustacea, Amphipoda, Leucothoidae)
}

\author{
James Darwin Thomas ${ }^{1, \dagger}$, Traudl Krapp-Schickel ${ }^{2, \neq}$ \\ I Nova Oceanographic Center, Dania, Florida, USA 2 Forschungsmuseum A. Koenig, Bonn, Germany \\ † urn:lsid:zoobank.org:author:44494135-041B-452C-8CDA-A20FF412930C \\ $\ddagger$ urn:lsid:zoobank.org:author:E1B1DCCF-04CB-4B1A-A69B-A7C25EC95A38 \\ Corresponding author: James Darwin Thomas (thomasjd@nova.edu)
}

Academic editor: Oliver Coleman | Received 31 January 2011 | Accepted 9 March 2011 | Published 28 April 2011

urn:lsid:zoobank.org:pub:A1FD8DA7-C01B-4B5E-9AEF-041990BDE8A1

Citation: Thomas JD, Krapp-Schickel T (2011) A new species of Leucothoid Amphipod, Anamixis bananarama, sp. n., from Shallow Coral Reefs in French Polynesia (Crustacea, Amphipoda, Leucothoidae). ZooKeys 92: 1-8. doi: 10.3897/zookeys.92.1036

\begin{abstract}
Both leucomorph and anamorph developmental stages of Anamixis bananarama sp. n., are illustrated and described from shallow back reef environments of Moorea, French Polynesia. Distinguished by vestigial first gnathopods that persist in post-transformational adult males, this is the second species in the genus to exhibit this unusual character. In other features such as coxae and second gnathopods $A$. bananarama sp. n. resembles other Pacific Plate endemics of Anamixis known from the region. Specific host association is not documented but suspected to be small calcareous asconoid sponges associated with coral rubble.
\end{abstract}

\section{Keywords}

Amphipod, Leucothoidae, sponge, Coral reefs, French Polynesia

\section{Introduction}

Leucothoid amphipods are of interest for their unusual ecology as commensal inhabitants of sessile invertebrates such as sponges, sea squirts, and bivalves. Obligate commensal species have evolved highly characteristic and unusual morphologies and feeding strategies as

Copyright JD Thomas, T Krapp-Schickel. This is an open access article distributed under the terms of the Creative Commons Attribution License, which permits unrestricted use, distribution, and reproduction in any medium, provided the original author and source are credited. 
a consequence of their way of life, including eusocial structure, a condition once thought limited to insects and naked mole rats. Duffy $(1996,2003)$ first documented eusocial behavior in marine sponge-inhabiting snapping shrimp. Thomas $(1983,1997)$ documented eusociality and communal living in highly derived tropical leucothoids in the genus Anamixis. Thiel (1999) reported on nest guarding in Leucothoe spinicarpa from Florida, USA. Because of their cryptic lifestyle and need for specialized collecting methods, leucothoid diversity has been vastly underrepresented in museum collections. Specialized in-situ underwater collecting techniques pioneered by the first author are beginning to reveal the extent of leucothoid diversity (Thomas, 1997, Thomas and Klebba, 2006, 2007; White and Thomas, 2010). The 22 species in genus Anamixis Stebbing, 1897, are primarily tropical - warm temperate in distribution. Their greatest diversity is in the Pacific with 14 species, followed by the Indian Ocean with five species, and the Caribbean Sea and Western Atlantic with four species. Further specialized collecting of host and symbiont will undoubtedly significantly expand the addition of new taxa in the Leucothoidae.

Thomas and Barnard (1983) announced the transformation of males of Leucothoides pottsi, originally belonging to Leucothoidae Dana, 1852, into hyperadult males of Anamixis hanseni belonging to Anamixidae Stebbing, 1897 [now Anamixis cavatura (Thomas, 1997)], but avoided synymymising the two families. In 2000, Lowry and colleagues merged the Anamixidae and Leucothoidae (Lowry et al, 2000). With the addition of both anamorph and leucomorph descriptions in A. bananarama sp. n. this proposed familial restructuring now comprises 139 species in six genera: Anamixis Stebbing, 1897 (22 spp.); Nepanamixis Thomas, 1997 (4 spp.); Paranamixis Schellenberg, 1938 (13 spp.); Leucothoe Leach, 1814 (96 spp.); Leucothoella Schellenberg, 1928 (2 spp.); and Paraleucothoe Stebbing, 1899 (2 spp.). A full taxonomic database for the Leucothoidae with hyperlinks to illustrations is available (Thomas, 1999) at: http:// www.nova.edu/ocean/jthomas/Current_Leucothoidae_7_09.pdf

In a study of leucothoids from Florida and Belize reefs, the first author and graduate students documented 43 invertebrate host species for Caribbean leucothoids (Thomas and Klebba 2006; 2007). These results combined with the recent addition of Lizard Island (Australia) species of leucothoids underscore the high level of undiscovered leucothoid diversity and illustrate how specialized field collecting can lead to new taxonomic discovery. Despite current taxonomic limitations, the Leucothoidae remain objects of intense interest due to their intriguing ecology, endocommensal lifestyle, and emerging biogeographic patterns.

\section{Methods}

Specimens were collected by snorkeling and SCUBA. Rubble and other shallow algal substrates were isolated in-situ and processed by elutriation. In the lab juvenile (leucomorph) and adult males (anamorphs) were separated and photographed using AutoMontage $^{\odot}$. Specimens were fixed in $100 \% \mathrm{ETOH}$ for molecular analysis and in $2 \%$ buffered formalin for dissection and illustration. Type material is deposited in the 
collections of the Florida Museum of Natural History in Gainesville, Florida with the prefix "UF" for museum numbers.

\section{Taxonomy}

\section{Anamixis bananarama sp. $\mathbf{n}$.}

urn:lsid:zoobank.org:act:C57C627F-D2F5-48CD-94C9-5868B6144F96

http://species-id.net/wiki/Anamixis_bananarama

Figures 1-3

Type material. Holotype, Anamorph male "A", $2.34 \mathrm{~mm}$, UF 26542, Paratype, leucomorph female "B", 2.10mm; UF 26543; Cook's Bay, Moorea, French Polynesia, J.D. Thomas collector, 4 December 2009, JDT Moorea 09-4 (South17.48220:West-149.82530). Wash of backreef rubble, 1-2m. Additional paratypes, female leucomorphs (7 specimens), UF 26544, Cook's Bay, Moorea, French Polynesia, J.D. Thomas collector, 11 December 2009, JDT-Moorea 09-10 (South 17.59205:West149.835211) coral rubble, coralgal sand, and coral heads, $2-3 \mathrm{~m}$.

Additional material. Hans-Georg Mueller collector; 27 February to 6 March 1988, shallow reef, Bora Bora.

Diagnosis. Terminal anamorph males: Eyes with 7 scattered ommatidia; gnathopod 1 greatly reduced, shriveled, persisting in post-transformational stages. Gnathopod 2, basis greatly elongated, narrow; carpus elongate, apically blunt, with reduced setal tufts on medial margin; propodus with sparse mediofacial setal row. Telson elongate for genus, 1.72 times longer than wide.

Description. Head margin broadly rounded, lacking any defining processes; ventral keel, anterior margin rounded, with small midapical indentation; eyes reduced, consisting of 7 scattered ommatidial facets. Antenna 1, ratio of segments 1-3, 43:33:28, peduncle segment 1 and 2 with 3 and 2 plumose setae respectively; flagellum 6-articulate, articles 3-6 with aesthetascs. Antenna 2, flagellum short, 4-articulate. Maxilliped, inner plates fused, apically produced, apical margin with small concave excavation; outer plates lacking inner lobes; palp article 4, 1.36 times length of article 3. Pereonite 1 with small lateral locking ridge.

Gnathopod 1, coxa greatly reduced, apically bifid; remainder of appendage a small bud, articles $2-5$ extremely reduced and shriveled. Gnathopod 2, coxa extending deeper than coxa 3-4, distal margin evenly rounded, bearing 10 mediodistal submarginal setules; basis thin, elongate; carpus slightly curved, blunt, reaching 85 percent of propodus, with 6 medial clusters of setae: $2:(2+3):(3+3):(4+1): 3: 1$, distal margin with 5 small submarginal setules; propodus with single row of 7 mediofacial feeding setae, extending 43 percent of propodus length, posterior margin smooth with 3 submarginal setae, anterior margin with 2 prominent apically truncate processes; dactyl straight, inner surface smooth with paired setae on small process near apex, reaching 83 percent on propodus. 


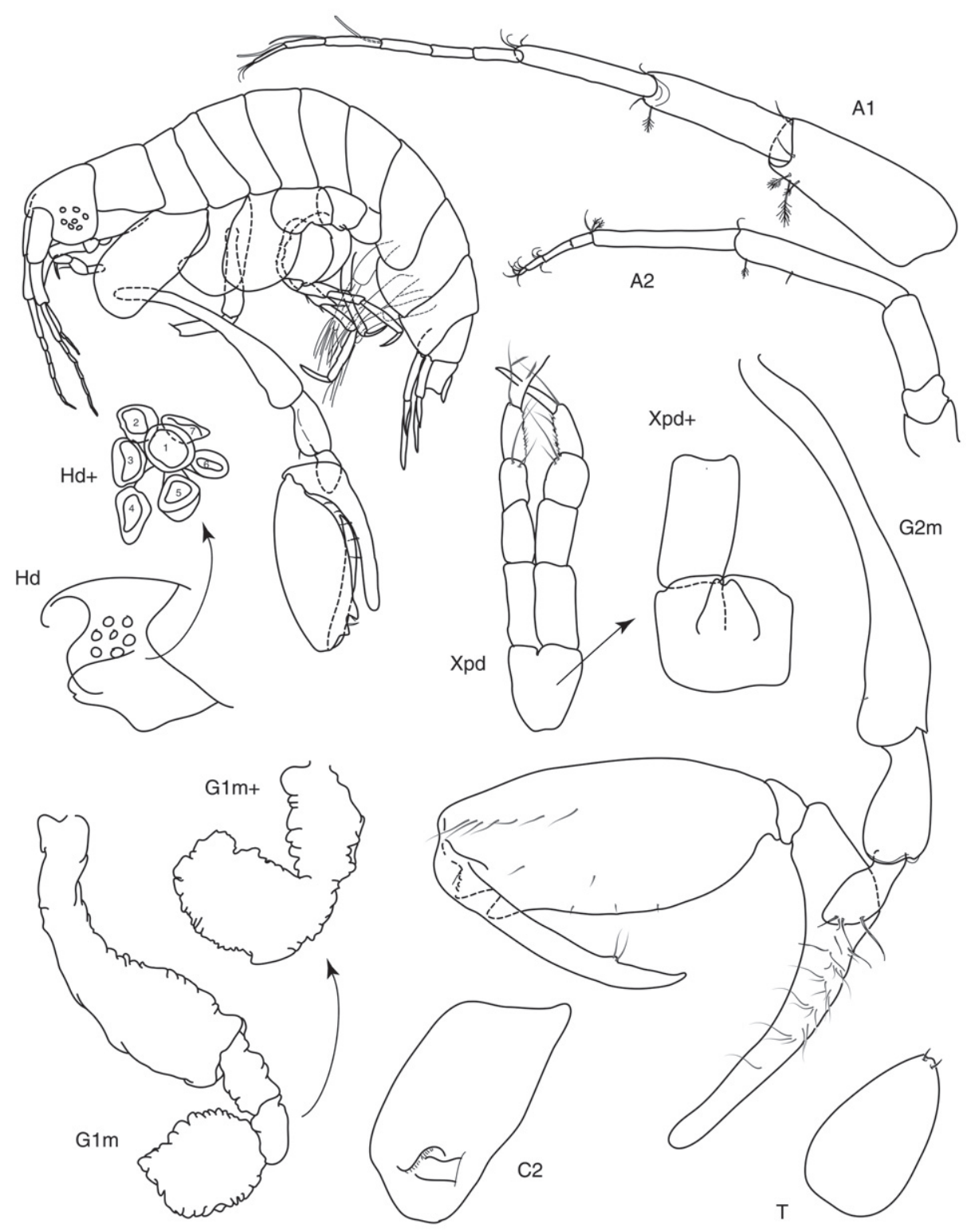

Figure I. A. bananarama sp. n., holotype, anamorph male male "A", $2.34 \mathrm{~mm}$.

Pereopod 3, coxa smaller than 4, rounded ventrally, anterior and posterior margins straight; remainder of pereopods unremarkable. Pereopod 4, coxa slightly larger than 3 , posterior margin slightly expanded, remainder of peropod similar to pereopod 3 . Pereopods 5-6, coxae bilobed; pereopod 7, coxa entire. Epimera normal for genus. Uropods 1-2, outer rami shortened, approximately 40 percent of inner ramus. Uropod 

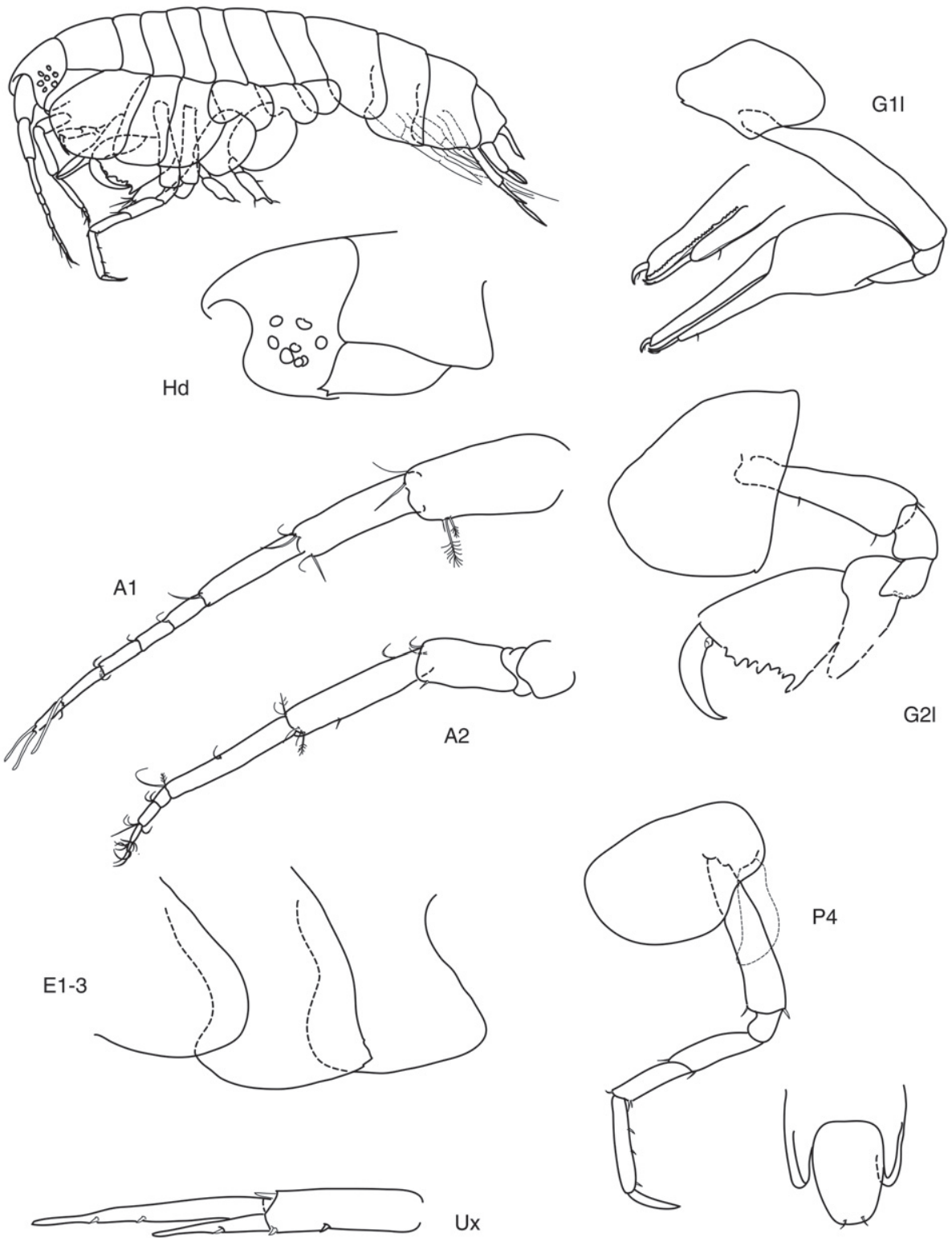

$\mathrm{T}$

Figure 2. A. bananarama sp. n., paratype, leucomorph female "B", $2.10 \mathrm{~mm}$.

3 , outer ramus 40 percent of inner ramus, outer and inner rami with 1 and 2 marginal spines respectively. Telson 1.70 times longer than wide, with 2 apical setae.

Leucomorph. Description of female leucomorph. Head, anterior margin rounded, smooth, eyes consisting of 7 scattered ommatidial facets. Antenna 1, ratio of segments 1-3, 33:26:23; flagellum 5-articulate, articles 4 and 5 with aesthetascs. Antenna 


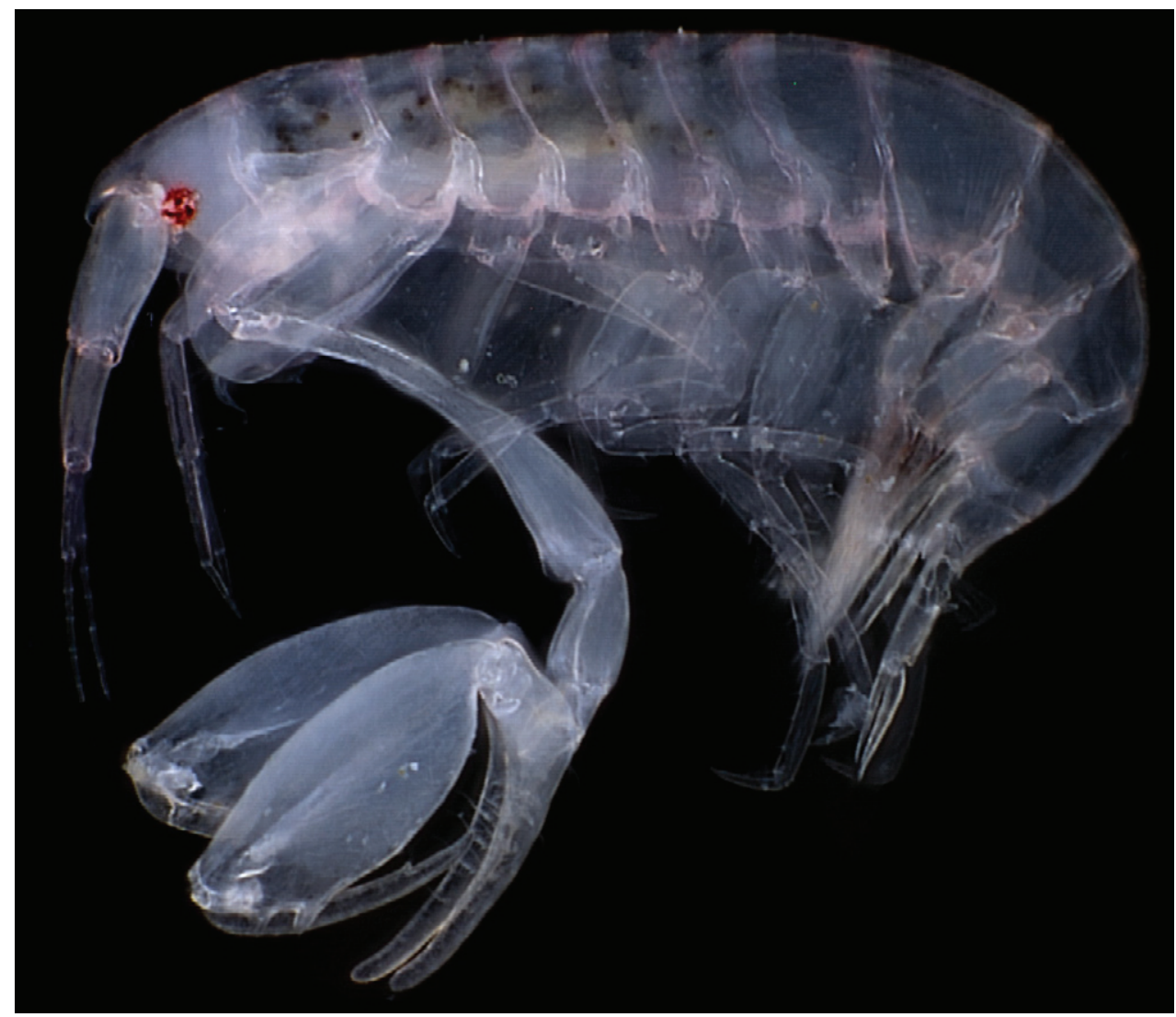

Figure 3. AutoMontage Z-stacked photograph of $A$. bananarama sp. n., holotype, anamorph male male "A", $2.34 \mathrm{~mm}$.

2, flagellum short, 5-articulate. Gnathopod 1, coxa moderately reduced, extending to ventral margin of head, apically bifid; carpus shorter than propodus, with two apical recurved spines, anterior margin bare; propodus, posterior margin finely serrate, bearing a thick recurved apical seta. Gnathopod 2, anterior margin of coxa broadly rounded, ventral margin slightly produced, posteroventral corner with small cusp, posterior margin straight; propodus, palm angle transverse, palmar margin defined by series of concavities and processes, corner of palm defined by distinct cusp; dactyl reaching to end of palm. Telson 1.72 times longer than wide, with 2 apical setae.

Etymology. This species is named for the long recurved carpal lobe on the second gnathopod that resembles the shape of a banana.

Relationships. Anamixis bananarama shares it closest affinity with A. jebbi from the Madang Lagoon, Papua New Guinea, (Thomas, 1997), with both species having 7 ommatidial facets in both leucomorph and anamorph stages, and a reduced, vestigial first gnathopod in the post transformational anamorph stage. The second gnathopod of $A$. bananarama differs from $A$. jebbi in the elongate basis, the more blunt and less 
setose carpus, and reduced mediofacial setal row (7 in A. bananarama; 14 in A. jebbi). A. bananarama exhibits an elongated telson typical of ratios found in Nepanamixis (Thomas, 1997). Both $A$. jebbi and A. bananarama show transitional characters placing them in a clade by themselves with the elongate telson of $A$. bananarama placing it nearer to Nepanamixis in this regard. The telson of $A$. bananarama at 1.70 times longer than wide exceeds that of $A$. jebbi at 1.32 and approaches the telson ratios typical of the genus Nepanamixis at 1.8-2.0 times longer than wide.

Remarks. Color in life and in freshly collected and preserved material of both leucomorph and anamorph stages are pale translucent pink. There is faint thin reddish banding on posterior thoracic and abdominal segments. Eyes are red. Ovigerous females contain an average of $7-10$ yellow eggs in the marsupium.

The vestigial first gnathopods found in $A$. bananarama and $A$. jebbi are persistent morphologies in post transformational anamorphs in both taxa. A number of specimens were examined by the first author to ensure these were not transitional transformational features as reported by Thomas (1997) in Paranamixis clarkae from the Seychelles Islands. In $P$. clarkae, transformational anamorphs exhibit small shrunken vestiges of gnathopod 1 which are lost in subsequent molts. Ren (2006) described $P$. vestigium from the South China Sea, illustrating similar reduced first gnathopods. In all other aspects $P$. vestigium resembles $P$. misakiensis described by Thomas (1997) from Japan and examination of a series of anamorph specimens of $P$. vestigium is needed to resolve whether these vestigial first gnathopods persist in post-transformational molts.

Habitat. Specific habitat/host undocumented but assumed to be small asconoid calcareous sponges in protected rubble habitats in backreef environments.

Distribution. Moorea and Bora Bora, French Polynesia, Pacific Ocean. 1-3m.

\section{Acknowledgements}

The first author was supported by the BioCode project with support from the Gordon and Betty Moore Foundation and a President's Faculty Research Grant from Nova Southeastern University. The first author was assisted in the field by Kristine White and Sharein El Tourky. Photographer David Littschwager, on assignment in Moorea for National Geographic Magazine, helped render color photographs of the type specimen in AutoMontage ${ }^{\odot}$. Colleagues Oliver Coleman and Alan Myers provided editorial improvements to the draft manuscript.

\section{References}

Duffy JE (1996) Eusociality in a coral-reef shrimp. Nature 381:512-514. doi:10.1038/381512a0 Duffy JE (2003) The ecology and evolution of eusociality in sponge-dwelling shrimp. In: Higashi S (Ed) Genes, behavior, and evolution in social insects. University of Hokkaido Press, Sapporo, Japan, 217-254. 
Ren D (2006) Fauna Sinica, Invertebrata, volume 41, Crustacea, Amphipoda, Gammaridea (i). Bejing, China, Science Press, 588 pp.

Thiel M (1999) Host-use and population demographics of the ascidian-dwelling amphipod Leucothoe spinicarpa: indication for extended parental care and advanced social behaviour. Journal of Natural History 1999 (33): 193-206. doi:10.1080/002229399300371

Thomas JD (1997) Systematics and Phylogeny of the commensal amphipod family Anamixidae (Crustacea: Amphipoda). Records of the Australian Museum, Volume 49: 35-98, figures $1-27-187$.

Thomas JD (1983) Biological monitoring and tropical biodiversity in marine environments: a critique with recommendations, and comments on the use of amphipods as bioindicators. Journal of Natural History, 27: 795-806. doi:10.1080/00222939300770481

Thomas JD, Barnard JL (1983) Transformation of the Leucothoides morph to the Anamixis morph (Amphipoda). Journal of Crustacean Biology 3(1): 154-157. doi:10.2307/1547860

Thomas JD, Klebba KN (2007) New species and host associations of commensal leucothoid amphipods from coral reefs in Florida and Belize (Crustacea: Amphipoda). Zootaxa 1494: 1-44, 27 figures.

Thomas JD Klebba KN (2006) Studies of commensal leucothoid amphipods: two new spongeinhabiting species from south Florida and the western Caribbean. Journal of Crustacean Biology 26(1): 13-22. doi:10.1651/C-2624.1

White KN, Thomas JD (2009) Leucothoidae. In: Lowry JK, Myers AA (Eds) Amphipoda of the Great Barrier Reef, Australia. Zootaxa 2260: 494-555. 